\title{
Salen-Cu(II) Complex Catalyzed $N$-Arylation of Imidazoles under Mild Conditions
}

\author{
Yan Liu, Qin Zhang, Xiaowei Ma, Ping Liu*, Jianwei Xie, Bin Dai, Zhiyong Liu \\ School of Chemistry and Chemical Engineering/Key Laboratory for Green Processing of Chemical Engineering of \\ Xinjiang Bingtuan, Shihezi University, Shihezi, China \\ Email: *liuping1979112@yahoo.com.cn
}

Received June 26, 2013; revised July 28, 2013; accepted August 8, 2013

Copyright (C) 2013 Yan Liu et al. This is an open access article distributed under the Creative Commons Attribution License, which permits unrestricted use, distribution, and reproduction in any medium, provided the original work is properly cited.

\begin{abstract}
Three inexpensive and air-/moisture-stable Salen-Cu complexes 1-3 were evaluated to be a novel class of catalysts for the $\mathrm{N}$-arylation of imidazoles with aryl halides. A variety of aryl iodides, bromides underwent the coupling with imidazoles, promoted by the complex $\mathbf{3}$, in moderate to excellent yields without the protection by an inert gas.
\end{abstract}

Keywords: Salen-Cu Complex; $N$-Arylation; Imidazole; Catalyze

\section{Introduction}

$N$-Aryl imidazoles and its derivatives are prevalent building blocks of numerous drugs, natural products and energetic materials, [1-5] and have been exploited as important precursors in $N$-heterocyclic carbene chemistry. $[6,7]$ Therefore, their preparation has been attracted much attention. In recent years, the transition-metal palladium catalyzed $N$-arylation of imidazoles has made remarkable achievements, and shows relative mild reaction conditions, broad substrate scope and excellent functional-group tolerance [8-10]. However, in comparison with the use of costly palladium, it is desirable to develop more effective copper catalytic systems for $N$-arylation of imidazoles. The breakthroughs in this area, which were achieved by two research groups of Buchwald [11,12] and Taillefer, [13] respectively, have typically been driven by the implementation of new class of ligands and only catalytic amounts of copper metal under mild conditions. Following these pioneering works, several classes of mono-, bidentate, and polydentate chelators have thereby been developed to expedite the reaction rates and substantially lower the reaction temperature of Cu-based C-N coupling reaction [14-27]. In spite of the significant progress made in the aforementioned transformation, more efficient, air stable and cheaper ligands or metal-complexes for facilitating these coupling reactions under relatively milder conditions are still in demand.

\footnotetext{
*Corresponding author.
}

Recently, our group had developed a series of effective catalysts, pyrrolecarbaldiminato- $\mathrm{Cu}$ complexes for C-N coupling reaction [28], and we previously reported Suzuki-Miyaura reaction catalyzed by Salen and half-salen palladium(II) complexes [29]. Although Salen-Pd complexes show low catalytic activity in the C-C coupling reaction, we reasonable assumed that Salen-Cu complexes might be a class of effective catalysts for the C-N coupling reaction. Herein, we wish to report Salen-Cu complexes as catalysts for the $\mathrm{N}$-arylation of imidazoles and its derivatives. This system contains several advantages as follows: 1) the complexes were easily synthesized from cheap starting materials, and stable in air and moisture; 2) the reaction condition was relatively milder and did not require the protection by an inert atmosphere; 3) the complexes worked well for aryl iodides, and bromides with moderate to excellent yields.

\section{Results and Discussion}

Initially, the catalytic activity of the complexes 1-3 evaluated by using the $\mathrm{C}-\mathrm{N}$ coupling of 4-iodotoluene with imidazole as a model reaction in the presence of $\mathrm{NaOH}$ at $120^{\circ} \mathrm{C}$ for $12 \mathrm{~h}$ in DMSO (Scheme 1). As expected, the three Salen-Cu complexes all exhibited high catalytic activity for this process, and which gave the desired product in 92\% - 94\% isolated yields (Table 1, entries 1-3). The coupling reaction did not occur in the absence of any catalyst (Table 1, entry 4). Subsequently, we select the complex $\mathbf{3}$ as catalyst to further investigate the effects of the other reaction conditions on the 


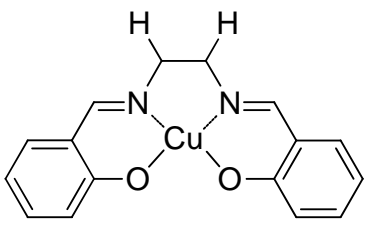

1

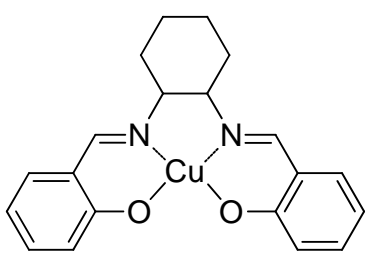

2

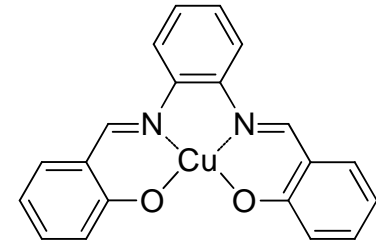

3

Scheme 1. Structure of complexes 1 - 3.

Table 1. Optimization of the reaction conditions ${ }^{\mathrm{a}}$.

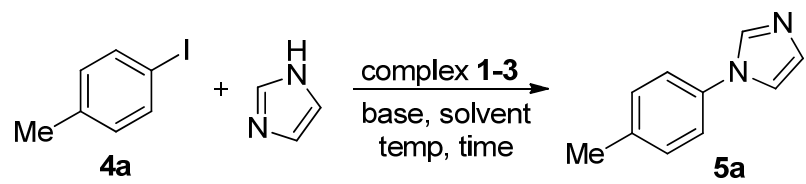

\begin{tabular}{|c|c|c|c|c|c|}
\hline Entry & Complex & Base & Solvent & Temp $\left({ }^{\circ} \mathrm{C}\right)$ & Yield (\%) \\
\hline 1 & - & $\mathrm{NaOH}$ & DMSO & 120 & 0 \\
\hline 2 & 1 & $\mathrm{NaOH}$ & DMSO & 120 & 92 \\
\hline 3 & 2 & $\mathrm{NaOH}$ & DMSO & 120 & 94 \\
\hline 4 & 3 & $\mathrm{NaOH}$ & DMSO & 120 & 94 \\
\hline 5 & 3 & $\mathrm{NaOH}$ & DMSO & 100 & 94 \\
\hline 6 & 3 & $\mathrm{NaOH}$ & DMSO & 80 & 88 \\
\hline 7 & 3 & $\mathrm{Na}_{2} \mathrm{CO}_{3}$ & DMSO & 100 & 0 \\
\hline 8 & 3 & $\mathrm{~K}_{3} \mathrm{PO}_{4}$ & DMSO & 100 & 70 \\
\hline 9 & 3 & $\mathrm{Cs}_{2} \mathrm{CO}_{3}$ & DMSO & 100 & 95 \\
\hline 10 & 3 & $\mathrm{NEt}_{3}$ & DMSO & 100 & 0 \\
\hline 11 & 3 & $\mathrm{NaOH}$ & DMF & 100 & 43 \\
\hline 12 & 3 & $\mathrm{NaOH}$ & DMA & 100 & 76 \\
\hline 13 & 3 & $\mathrm{NaOH}$ & $\mathrm{H}_{2} \mathrm{O}$ & 100 & 0 \\
\hline 14 & 3 & $\mathrm{NaOH}$ & DMSO & 100 & $82^{c}$ \\
\hline
\end{tabular}

a Reaction conditions: 4-ioidotoluene $(0.5 \mathrm{mmol})$, imidazole $(1.0 \mathrm{mmol})$, complex 1-3 (10 mol\%), base $(1.0 \mathrm{mmol})$, and solvent $(1 \mathrm{ml})$, reaction time 12 h. ${ }^{\text {b }}$ Isolated yields. ${ }^{\mathrm{c}}$ Complex 3 (5.0 mol\%).

$\mathrm{N}$-arylation reaction, including reaction temperature, base, solvent and catalyst loading. The results showed that $100^{\circ} \mathrm{C}$ was enough for the coupling reaction to give $94 \%$ yield of the product (Table 1, entry 5), and the lower temperature decelerated the reaction rate. For example, $88 \%$ yield was obtained when the reaction was carried out at $80^{\circ} \mathrm{C}$ (Table 1, entry 6). Base also plays an important role in the catalyst systems. Among various bases examined, $\mathrm{K}_{3} \mathrm{PO}_{4}$, and $\mathrm{Cs}_{2} \mathrm{CO}_{3}$ were all effective for the catalysis, and $\mathrm{Cs}_{2} \mathrm{CO}_{3}$ demonstrated the best improvement to give the corresponding product in $95 \%$ yield (Table 1, entries 8 and 9), but the use of $\mathrm{Na}_{2} \mathrm{CO}_{3}$ and organic base $\mathrm{NEt}_{3}$ led to lower yields (Table 1, entries 7 and 10). However, $\mathrm{NaOH}$ was used in the following studies because it was less expensive than $\mathrm{Cs}_{2} \mathrm{CO}_{3}$. Solvent is another important factor affecting catalysis. It was found that DMSO performed as the prime solvent. Both DMF and DMA were not as good as DMSO. Meanwhile, $\mathrm{H}_{2} \mathrm{O}$ was not suitable as a solvent (Table 1, entries 1113). Furthermore, decreasing the loading of complex 3 from $10 \mathrm{~mol} \%$ to $5 \mathrm{~mol} \%$ led to a decrease of the yield (Table 1, entry 14). Finally, the combination of Salen-Cu complex 3 (10 mol\%), $\mathrm{NaOH}$ (2 equiv.) at $100^{\circ} \mathrm{C}$ for 12 $\mathrm{h}$ in DMSO was chosen as the optimal conditions for $\mathrm{N}$-arylation of imidazole with 4-iodotoluene.

The scope of substrates was then investigated by using this catalytic system under the optimized reaction conditions. As shown in Table 2, In general, most of aryl iodides reacted with imidazole smoothly afforded the desired products in moderate to excellent yields. For example, 1-chloro-4-iodobenzene, 1-fluoro-4-iodobenzene and 4-iodo-1,1'-biphenyl led to the $N$-arylated products in 90\% - 95\% yields (Table 2, entries 6-8). When 1-(4-iodophenyl)ethanone and 1-iodo-4-nitrobenzene as coupling partners, the yields dropped to $72 \%$ and $60 \%$ respectively (Table 2, entries 4 and 5). Furthermore, the catalytic system could tolerate a variety of functional groups including the nitro, acetyl, and ether groups. Notably, sterically demanding ortho substituents such as 1-iodo-2-methylbenzene did not hamper the arylation reaction (Table 2, entry 3). Next, we were intrigued by the possibility of using aryl bromides as coupling partners. However, low yields were found under the previously optimized reaction conditions (Table 2, entries 9 and 10). In an endeavor to expand the scope of the methodology, this new catalytic system was applied to a variety of imidazole derivatives. To our delight, most of the aryl iodides reacted with the $1 H$-benzo[ $d]$ imidazole to provide the corresponding products in good to excellent yields $(80 \%$ - 92\%) under the optimized reaction conditions. Electron-withdrawing groups seemed to be a little beneficial for the catalysis compared to electrondonating ones. For example, 1-chloro-4-iodoben-zene, 1-fluoro-4-iodobenzene and 1-iodo-4-nitrobenzene afforded the corresponding arylated products in $80 \%-92 \%$ yields (Table 2, entries 14, 16 and 17). Furthermore, aryl iodides with electron-donating could also be coupled with imidazole to give the products in good yields (Table 2, entries 11 and 15). Sterically hindered 1-iodo-2-methylbenzene afforded the product in low yield (Table 2, entry 13). 
Table 2. $N$-Arylation of imidazole with aryl halides catalyzed by complex $3^{\mathrm{a}}$.

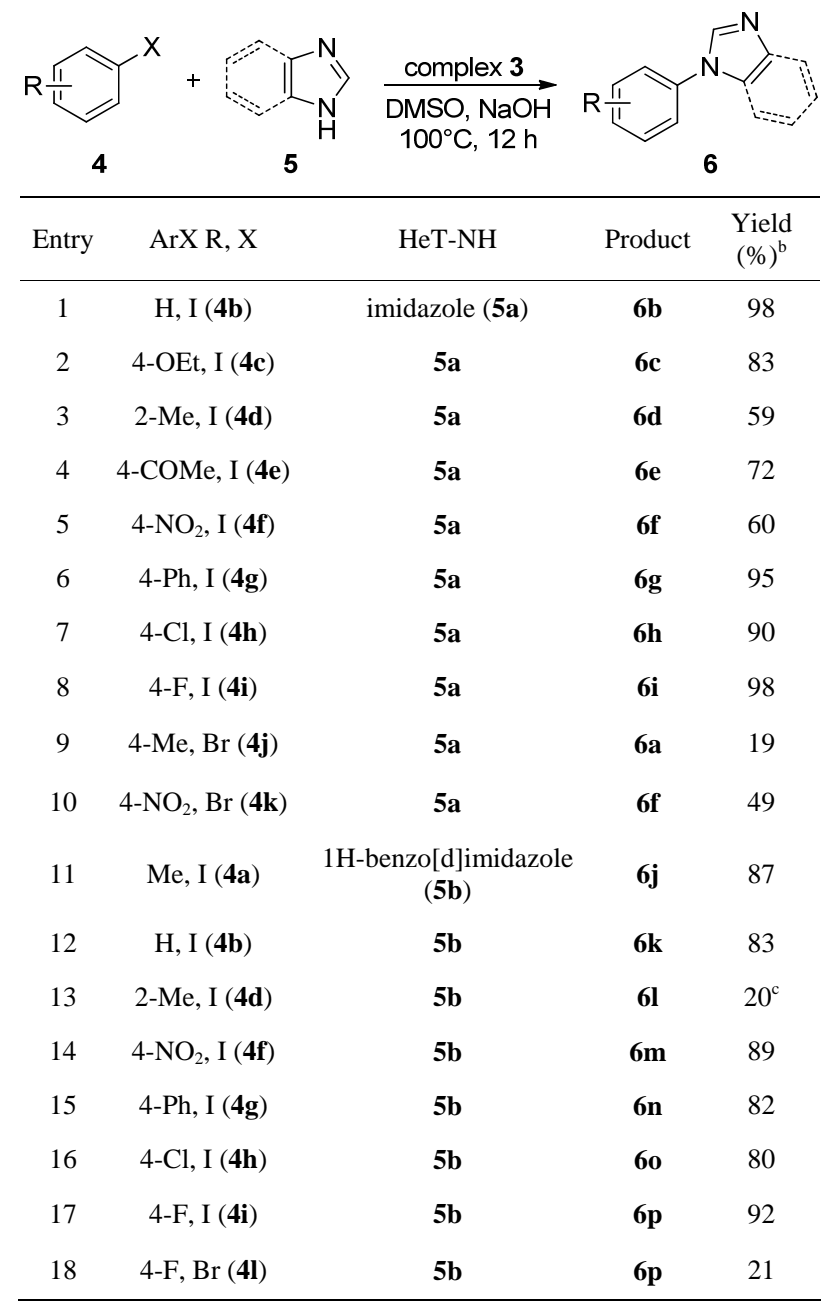

${ }^{\text {a }}$ Reaction conditions: aryl halides $(0.5 \mathrm{mmol})$, imidazoles $(1.0 \mathrm{mmol})$, complex 3 (10 mol\%), NaOH (1.0 mmol), and DMSO (1 ml), 100 $\mathrm{C}, 12 \mathrm{~h} .{ }^{b}$ Isolated yields.

\section{Conclusion}

In summary, we have developed a novel and general catalytic method for $N$-arylation of imidazoles promoted by Salen-Cu(II) complex 3 . The system is efficient for the coupling of imidazoles and its derivatives with $\mathrm{ArX}$ $(\mathrm{X}=\mathrm{I}, \mathrm{Br})$ to give moderation to excellent yields. The easy availability of the catalyst, mild reaction conditions, experimental simplicity, and broad substrate scope are the features of the catalytic method presented in the current paper. Further application of these Salen-Cu(II) complexes catalyzed organic reaction is currently ongoing in our laboratory.

\section{Experimental}

\subsection{Materials and Instruments}

All reactions were carried out under air using magnetic stirring unless otherwise noted. ${ }^{1} \mathrm{H}$ NMR spectral data were recorded on a Bruker DPX-400 spectrometer using TMS as internal standard and $\mathrm{CDCl}_{3}$ as solvent. Mass spectra were recorded on GC-MS (Agilent 7890A/5975C) instrument under EI model. All other reagents were of analytical grade quality purchased commercially and used.

\subsection{Synthesis of Complexes 1-3}

$\mathrm{Cu}(\mathrm{OAc})_{2} \cdot \mathrm{H}_{2} \mathrm{O}(0.012 \mathrm{~mol}, 2.40 \mathrm{~g})$ was added to a solution of substituted ethane-1,2-diamine $(0.01 \mathrm{~mol})$ and 2-hydroxybenzaldehyde $(0.02 \mathrm{~mol})$ in $35 \mathrm{ml}$ methanol. The mixture was stirred at $60^{\circ} \mathrm{C}$ for $5 \mathrm{~h}$ and then filtered. The precipitate was washed with dichloromethane. The solid product was collected and dried under vacuum to afford the desired complex 1-3.

Complex 1 [30,32]: yield 65\%. Anal. Calcd. for $\mathrm{C}_{16} \mathrm{H}_{14} \mathrm{CuN}_{2} \mathrm{O}_{2}$, \%: C, 58.26; H, 4.28; N, 8.49; Found, \%: C, 57.59; H, 4.38; N, 8.37.

Complex 2 [31,33,34]: yield 70\%. Anal. Calcd. for $\mathrm{C}_{20} \mathrm{H}_{20} \mathrm{CuN}_{2} \mathrm{O}_{2}$, \%: C, 62.57; H, 5.25; N, 7.30; Found, \%: C, 62.72; H, 5.26; N, 7.49.

Complex 3 [34-37]: yield 72\%. Anal. Calcd. for $\mathrm{C}_{20} \mathrm{H}_{14} \mathrm{CuN}_{2} \mathrm{O}_{2}$, \%: C, 63.57; H, 3.73; N, 7.41; Found, \%: C, 63.45; H, 3.81; N, 7.45.

\subsection{General Procedure for $N$-Arylation of Imidazole with 4-Iodotoluene}

To a $10 \mathrm{ml}$ of sealed tube was added complex 3 (37.8 mg, $0.05 \mathrm{mmol})$, 4-iodotoluene (109 mg, $0.5 \mathrm{mmol})$, imidazole (68 mg, $1.0 \mathrm{mmol}$ ), $\mathrm{NaOH}$ (40 mg, $1.0 \mathrm{mmol}$ ), and DMSO $(1 \mathrm{ml})$. The reaction mixture was reacted at $100^{\circ} \mathrm{C}$ in a preheated oil bath for $12 \mathrm{~h}$. The reaction mixture was cooled to r.t., diluted with $10 \mathrm{~mL} \mathrm{H}_{2} \mathrm{O}$, and then the mixture was extracted with ethyl acetate $(3 \times 20 \mathrm{~mL})$. The combined organic phases was washed with water and brine, dried over anhydrous $\mathrm{Na}_{2} \mathrm{SO}_{4}$, and concentrated in vacuo. The residue was purified by flash column chromatograph on silica gel (ethyl acetate/petroleum ether, 2:1 to pure ethyl acetate) to afford the target product (75 mg, 95\% yield). 1-p-Tolyl-1H-imidazole (6a) [38-40], ${ }^{1} \mathrm{H}$ NMR $\left(400 \mathrm{MHz}, \mathrm{CDCl}_{3}\right): \delta 7.81(\mathrm{~s}, 1 \mathrm{H})$, 7.27 (s, 4H), 7.24 (t, $J=1.2 \mathrm{~Hz}, 1 \mathrm{H}), 7.19$ (s, 1H), 2.40 (s, 3H). GC-MS (EI): m/z $=158[\mathrm{M}]^{+}$.

\section{Acknowledgements}

We gratefully acknowledge financial support of this work by the National Basic Research Program of China (973 Program: 2012CB722603), the National Natural Science Foundation of China (No. 21103114), the Ministry of Education Innovation Team (No. IRT1161), and Start-Up Foundation for Young Scientists of Shihezi 
University (RCZX201012, RCZX201014, RCZX201015).

\section{REFERENCES}

[1] C. Jacobs, M. Frotscher, G. Dannhardt and R. W. Hartmann, "1-Imidazolyl(alkyl)-Substituted Di- and Tetrahydroquinolines and Analogues: Syntheses and Evaluation of Dual Inhibitors of Thromboxane $\mathrm{A}_{2}$ Synthase and Aromatase," Journal of Medicinal Chemistry, Vol. 43, No. 9, 2000, pp. 1841-1851. doi:10.1021/jm991180u

[2] J. Zhong, "Muscarine, Imidazole, Oxazole and Thiazole Alkaloids," Natural Product Reports, Vol. 22, No. 2, 2005, pp. 196-229. doi:10.1039/b316104h

[3] C. Kison and T. Opatz, "Modular Synthesis of Tetrasubstituted Imidazoles and Trisubstituted Oxazoles by Aldimine Cross-Coupling," Chemistry - A European Journal, Vol. 15, No. 4, 2009, pp. 843-845. doi:10.1002/chem.200802175

[4] H. Gao and J. M. Shreeve, "Azole-Based Energetic Salts,” Chemical Reviews, Vol. 111, No. 11, 2011, pp. 7377- 7436. doi:10.1021/cr200039c

[5] S. Fujishima, R. Yasui, T. Miki, A. Ojida and I. Hamachi, "Ligand-Directed Acyl Imidazole Chemistry for Labeling of Membrane-Bound Proteins on Live Cells," Journal of the American Chemical Society, Vol. 134, No. 9, 2012, pp. 3961-3964. doi:10.1021/ja2108855

[6] D. Enders, O. Niemeier and A. Henseler, "Organocatalysis by $N$-Heterocyclic Carbenes," Chemical Reviews, Vol. 107, No. 2, 2007, pp. 5606-5655. doi:10.1021/cr068372z

[7] L. Benhamou, E. Chardon, G. Lavigne, S. BelleminLaponnaz and V. César, "Synthetic Routes to $N$-Heterocyclic Carbene Precursors,” Chemical Reviews, Vol. 111, No. 4, 2011, pp. 2705-2733. doi:10.1021/cr100328e

[8] F. Monnier and M. Taillefer, "Catalytic C-C C-N, and C-O Ullmann-Type Coupling Reactions,” Angewandte Chemie International Edition, Vol. 48, No. 38, 2009, pp. 6954-6971.doi:10.1002/anie.200804497

[9] D. S. Surry and S. L. Buchwald, "Dialkylbiaryl Phosphines in Pd-Catalyzed Amination: A User's Guide," Chemical Science, Vol. 2, No. 1, 2011, pp. 27-50.

[10] D. Maiti, B. P. Fors, J. L. Henderson, Y. Nakamura and S. L. Buchwald, "Palladium-Catalyzed Coupling of Functionalized Primary and Secondary Amines with Aryl and Heteroaryl Halides: Two Ligands Suffice in Most Cases,” Chemical Science, Vol. 2, No. 1, 2011, pp. 57-68. doi:10.1039/c0sc00330a

[11] S. L. Buchwald, A. Klapars, J. C. Antilla, G. E. Job, M. Wolter, F. Y. Kwong, G. Nordmann and E. J. Hennessy, "Copper-Catalyzed Formation of Carbon-Heteroatom and Carbon-Carbon Bonds,” US 2001 0286286-WO02/085838.

[12] A. Klapars, J. C. Antilla, X. Huang and S. L. Buchwald, "A General And Efficient Copper Catalyst for the Amidation of Aryl Halides and the $\mathrm{N}$-Arylation of Nitrogen Heterocycle," Journal of the American Chemical Society, Vol. 123, No. 31, 2001, pp. 7727-7729. doi:10.1021/ja016226z

[13] M. Taillefer, H.-J. Cristau, P. P. Cellier, J.-F. Spindler and A. Ouali, "Method for Forming a Carbon-Carbon or Carbon-Heteroatom Linkage,” Fr 2001, 16547-WO035 3225.

[14] A. Klapars, X. Huang and S. L. Buchwald, “A General and Efficient Copper Catalyst for the Amidation of Aryl Halides," Journal of the American Chemical Society, Vol. 124, No. 25, 2002, pp. 7421-7428. doi:10.1021/ja0260465

[15] Z. Lu and R. Twieg, "Copper-Catalyzed Aryl Amination in Aqueous Media with 2-Dimethylaminoethanol Ligand," Tetrahedron Lettersers, Vol. 46, No. 17, 2005, pp. 2997-3001. doi:10.1016/j.tetlet.2005.03.027

[16] H. Rao, H. Fu, Y. Jiang and Y. Zhao, "Copper-Catalyzed Arylation of Amines Using Diphenyl Pyrrolidine-2Phosphonate as the New Ligand,” The Journal of Organic Chemistry, Vol. 70, No. 20, 2005, pp. 8107-8109. doi:10.1021/jo051221w

[17] H. Zhang, Q. Cai and D. Ma, "Amino Acid Promoted CuI-Catalyzed C-N Bond Formation between Aryl Halides and Amines or $\mathrm{N}$-Containing Heterocycles," The Journal of Organic Chemistry, Vol. 70, No. 13, 2005, pp. 5164-5173. doi:10.1021/jo0504464

[18] Y. Chen and H. Chen, "1,1,1-Tris(hydroxymethyl)ethane as A New, Efficient, and Versatile Tripod Ligand for Copper-Catalyzed Cross-Coupling Reactions of Aryl Iodides with Amides, Thiols, and Phenols," Organic Letters, Vol. 8, No. 24, 2006, pp. 5609-5612. doi:10.1021/ol062339h

[19] M. Yang and F. Liu, "Diamine Ligands in Copper-Catalyzed Reactions, An Ullmann Coupling of Aryl Iodides and Amines Using An Air-Stable Diazaphospholane Ligand," The Journal of Organic Chemistry, Vol. 72, No. 23, 2007, pp. 8969-8971. doi:10.1021/jo0712291

[20] P. Suresh and K. Pitchumani, "Per-6-amino- $\beta$-cyclodextrin as An Efficient Supramolecular Ligand and Host for $\mathrm{Cu}(\mathrm{I})$-Catalyzed $\mathrm{N}$-Arylation of Imidazole with Aryl Bromides," The Journal of Organic Chemistry, Vol. 73, No. 22, 2008, pp. 9121-9124. doi:10.1021/jo801811w

[21] D. Wang and K. Ding, "2-Pyridinyl $\beta$-Ketones as New Ligands for Room-Temperature CuI-Catalysed C-N Coupling Reactions,” Chemical Communications, No. 14, 2009, pp. 1891-1893. doi:10.1039/b821212k

[22] H. Zhao, H. Fu and R. Qiao, “Copper-Catalyzed Direct Amination of Ortho-Functionalized Haloarenes with Sodium Azide as the Amino Source," The Journal of Organic Chemistry, Vol. 75, No. 10, 2010, pp. 3311-3316. doi:10.1021/jo100345t

[23] K. G. Thakur, K. S. Srinivas, K. Chiranjeevi and G. Sekar, "D-Glucosamine as An Efficient Ligand for the CopperCatalyzed Selective Synthesis of Anilines from Aryl Halides and $\mathrm{NaN}_{3}$," Green Chemistry, Vol. 13, No. 9, 2011, pp. 2326-2329. doi:10.1039/c1gc15469a

[24] D. Wang, F. Zhang, D. Kuang, J. Yu and J. Li, “A Highly Efficient Cu-Catalyst System for $\mathrm{N}$-Arylation of Azoles in Water," Green Chemistry, Vol. 14, No. 5, 2012, pp. 1268-1271. doi:10.1039/c2gc35077g

[25] Z. Q. Wu, Z. Q. Jiang, D. Wu, H. F. Xiang and X. G. Zhou, "A Simple and Efficient Catalytic System for Coupling Aryl Halides with Aqueous Ammonia in Water," 
European Journal of Organic Chemistry, Vol. 2010, No. 10, 2010, pp. 1854-1857. doi:10.1002/ejoc.201000060

[26] Z. Q. Wu, L. Zhou, Z. Q. Jiang, D. Wu, Z. K. Li and X. G. Zhou, "Sulfonato-Cu(salen) Complex Catalyzed $N$-Arylation of Aliphatic Amines with Aryl Halides in Water," European Journal of Organic Chemistry, Vol. 2010, No. 26, 2010, pp. 4971-4975. doi:10.1002/ejoc.201000840

[27] Y. Wang, Z. Wu, L. X. Wang, Z. K. Li and X. G.Zhou, "A Simple and Efficient Catalytic System for $N$-Arylation of Imidazoles in Water," Chemistry-A European Journal, Vol. 15, No. 36, 2009, pp. 8971-8974. doi:10.1002/chem.200901232

[28] Y. L. Jiao, N. N. Yan, J. W. Xie, X. W. Ma, P. Liu and B. Dai, "A Simple and Efficient Copper(II) Complex as a Catalyst for $N$-Arylation of Imidazoles," Chinese Journal of Chemistry, Vol. 31, No. 2, 2013, pp. 267-270. doi:10.1002/cjoc.201201121

[29] P. Liu, X.-J. Feng and R. He, "Salen and Half-Salen Palladium(Ii) Complexes: Synthesis, Characteriztion and Catalytic Activity toward Suzuki-Miyaura Reaction,” Tetrahedron, Vol. 66, No. 3, 2010, pp. 631-636. doi:10.1016/j.tet.2009.11.072

[30] N. I. Giricheva, G. V. Girichev, N. P. Kuzmina, Y. S. Medvedeva, A. Y. Rogachev, "Structure of the $\mathrm{Cu}$ (Salen) Molecule, $\mathrm{CuO}_{2} \mathrm{~N}_{2} \mathrm{C}_{16} \mathrm{H}_{14}$, According to Gas-Phase Electron Diffraction Data and Quantum Chemical Calculations," Journal of Structural Chemistry, Vol. 50, No. 1, 2009, pp. 52-59. doi:10.1007/s10947-009-0007-1

[31] Y. N. Belokon, R. G. Davies, J. A. Fuentes and M. North, "The Influence of Imine Structure, Catalyst Structure and Reaction Conditions on the Enantioselectivity of the Alkylation of Alanine Methyl Ester Imines Catalyzed by Cu(ch-salen)," Tetrahedron Letters, Vol. 42, No. 45, 2001, pp. 8093-8096. doi:10.1016/S0040-4039(01)01718-X

[32] Y. L. Wen, W. Huang, B. Wang, J. C. Fan, Z. H. Gao and L. H. Yin, "Synthesis of Salicylaldehyde Schiff Base Modified Cu Nanocrystals by Thermal Treatment in Liquid Paraffin,” Applied Surface Science, Vol. 258, No. 2, 2011, pp. 946-949. doi:10.1016/j.apsusc.2011.09.033

[33] Y. N. Belokon, M. North, T. D. Churkina, N. S. Ikonnikova and V. I. Maleev, "Chiral Salen-Metal Complexes as
Novel Catalysts for the Asymmetric Synthesis of A-Amino Acids under Phase Transfer Catalysis Conditions," Tetrahedron, Vol. 57, No. 13, 2001, pp. 2491-2498. doi:10.1016/S0040-4020(01)00072-2

[34] S. Sabarinathan, G. Vasuki, P. S. Rao, "Chiral Cu(II) Salen Complexes Catalyzed Aerobic Oxidative Biaryl Coupling Probing the Reaction by EPR,” Chemistry-A European Journal, Vol. 1, No. 4, 2010, pp. 360-367. doi:10.5155/eurjchem.1.4.360-367.221

[35] M. G. B. Drew, J. F. Godsell, S. Roy, G. Mukhopadhyay and D. Maity, "Synthesis and Characterization of $\mathrm{Cu}(\mathrm{II})$ Complexes of Tetradentate and Tridentate Symmetrical Schiff Base Ligands Involving O-Phenelenediamine, Salicylaldehyde and Diacetylmonoxime," Transition Metal Chemistry, Vol. 35, No. 2, 2010, pp. 197-204. doi:10.1007/s11243-009-9314-9

[36] M. M. Abd-Elzaher, "Synthesis and Spectroscopic Characterization of Some Tetadentate Schiff Bases and Their Nickel, Copper and Zinc Complexes,” Synthesis and Reactivity in Inorganic and Metal-Organic Chemistry, Vol. 30, No. 9, 2000, pp. 1805-1816.

[37] M. Salavati-Niasari, M. Shakouri-Arani and F. Davar, "Flexible Ligand Synthesis, Characterization and Catalytic Oxidation of Cyclohexane with Host (Nanocavity of zeoLite-Y)/Guest (Mn(II), Co(II), Ni(II) and Cu(II) Complexes of Tetrahydro-salophen) Nanocomposite Materials,” Microporous Mesoporous Mater, Vol. 116, No. 1-3, 2008, pp. 77-85. doi:10.1016/j.micromeso.2008.03.015

[38] M. Taillefer, N. Xia and A. Ouali, "Efficient Iron/Copper Co-Catalyzed Arylation of Nitrogen Nucleophiles,” Angewandte Chemie International Edition, Vol. 46, No. 6, 2007, pp. 934-936.doi:10.1002/anie.200603173

[39] H.-C. Ma and X.-Z. Jiang, " $N$-Hydroxyimides as Efficient Ligands for the Copper-Catalyzed $N$-Arylation of Pyrrole, Imidazole, and Indole,” The Journal of Organic Chemistry, Vol. 72, No. 23, 2007, pp. 8943-8946. doi:10.1021/jo7015983

[40] J. P. Collman, M. Zhong, L. Zeng and S. Costanzo, “The $[\mathrm{Cu}(\mathrm{OH}) \cdot \mathrm{TMEDA}]_{2} \mathrm{Cl}_{2}$-Catalyzed Coupling of Arylboronic Acids with Imidazoles in Water," The Journal of Organic Chemistry, Vol. 66, No. 4, 2001, pp. 1528-1531. doi:10.1021/jo0016780 